\title{
Estimation of Beta-Lactam Antibiotics-Serum Albumin Conjugated Proteins by High Performance Liquid Chromatography with Ultraviolet Detector
}

\section{Hung $\mathrm{YW}^{1,2}$, Lin $\mathrm{YH}^{2}$, Lin $\mathrm{YF}^{3}$, Wang WS ${ }^{3}$, Chiu $\mathrm{CF}^{4}$, Chiu $\mathrm{CC}^{5}$, Chiu $\mathrm{HW}^{6}$ and Hung $\mathrm{SW}^{\star 2,5}$}

${ }^{1}$ Institute of Cellular and System Medicine, National Health Research Institutes, Maioli, Taiwan

${ }^{2}$ Nursing Department of Yuanpei University, Xiangshan, Hsinchu, Taiwan

${ }^{3}$ Department of Veterinary Medicine, College of Veterinary Medicine, National Chung Hsing University, Taichung, Taiwan ${ }^{4}$ Graduate Institute of Metabolism and Obesity Sciences, College of Nutrition, Taipei Medical University, Taipei, Taiwan ${ }^{5}$ Division of Animal Resources, Animal Technology Laboratories, Agricultural Technology Research Institute, Xiangshan, Hsinchu, Taiwan

${ }^{6}$ Department of Biotechnology and Bioindustry Sciences, College of Bioscience and Biotechnology, National Cheng Kung University, Tainan, Taiwan

${ }^{*}$ Corresponding author: Hung SW, Nursing Department of Yuanpei University, Xiangshan, Hsinchu 300, Taiwan; Division of Animal Resources, Animal Technology Laboratories, Agricultural Technology Research Institute, Xiangshan, Hsinchu 300, Taiwan, Fax: +886-37-585735, Tel: +886-37-585930, E-mail: lymphoma2002@yahoo.com.tw

Citation: Hung YW, Lin YH, Lin YF, Wang WS, Chiu CF, et al. (2018) Estimation of Beta-Lactam AntibioticsSerum Albumin Conjugated Proteins by High Performance Liquid Chromatography with Ultraviolet Detector. J Antibio Res 2(1): 103

Received Date: March 02, 2018 Accepted Date: May 24, 2018 Published Date: May 25, 2018

\begin{abstract}
Background: $\beta$-lactam antibiotics represented the oldest class of antibiotics used in the treatment of infections in human being, livestock, and aquaculture. Drugs residues in the edible tissues or foodstuffs of animal pose a potential threat to human health. At present, extensive antibiotic resistant strains are now being detected and the development of antibiotic-resistant strains of epidemic and zoonotic pathogens is a major concern. Therefore, the purpose of this study was to estimate the extent of $\beta$-lactam antibiotics-HSA/BSA conjugations via three conjugation methods by using high performance liquid chromatography (HPLC) with ultraviolet (UV) detector. We wish that the technique will be applied to preliminarily detect the residues of $\beta$-lactam antibiotics may persist in edible tissues or foodstuffs in the livestock and aquaculture farms in clinical.

Materials and Methods: Three $\beta$-lactam antibiotics, amoxicillin (AMX), ampicillin (AM), and penicillin G (PG), were conjugated respectively with HSA or BSA following the carbodiimide-mediated coupling method (CCM), glutaraldehyde-mediated coupling method (GCM), and physiological coupling method (PCM). We designed our technique according to the absorption characteristics of the $\beta$-lactam antibiotics, human or bovine serum albumin (HSA or BSA), and $\beta$-lactam antibiotics-HSA or BSA conjugates and detected by HPLC with UV detector.

Results: Preparation and detection of the $\beta$-lactam antibiotics-HSA/BSA conjugates, $\beta$-lactam antibiotics, serum albumins (SA) via HPLC with UV detector. Data were shown that the obvious peaks of these conjugates were different from BSA or HSA. Furthermore, no other peaks of proteins were observed during the conjugates detection. Thus, $\beta$-lactam antibiotics (AMX, AM, and PG) and SA (HSA and BSA) conjugation based on three conjugated methods, CCM, GCM, and PCM and detection method, HPLC with UV detector, were able to successfully detect $\beta$-lactam antibiotics-SA conjugates.

Conclusion: Our technique (conjugated methods and detection method) may be a valuable tool for the detection of drug-carrier conjugated antigens, especially for $\beta$-lactam antibiotics-SA conjugates. The technique will be applied to preliminarily detect the residues of $\beta$-lactam antibiotics may persist in edible tissues or foodstuffs in the livestock and aquaculture farms in clinical.

Keywords: $\beta$-lactam Antibiotics; Carbodiimide-Mediated Coupling Method; Glutaraldehyde-Mediated Coupling Method; High Performance Liquid Chromatography; Physiological Coupling Method

List of abbreviations: AM: Ampicillin; AMX: Amoxicillin; BSA: Bovine Serum Albumin; CCM: Carbodiimide-Mediated Coupling Method; GCM: Glutaraldehyde-Mediated Coupling Method; H-NMR: Proton Nuclear Magnetic Resonance; HPLC: High Performance Liquid Chromatography; HSA: Human Serum Albumin; MW: Molecule Weight; PBS: Phosphate Buffer Saline, PCM: Physiological Coupling Method; PG: Penicillin G; SA: Serum Albumin; SDS-PAGE: Sodium Dodecyl Sulfate Polyacrylamide Gel Electrophoresis; TFA: Trifluoracetic Acid; UV/VIS: Ultraviolet/Visible
\end{abstract}




\section{Introduction}

The prototype $\beta$-lactam is penicillin, a natural compound first isolated in 1928. Modifications of side chains of penicillin eventually led to the discovery of various related compounds with different pharmacodynamic and pharmacokinetic properties, antimicrobial spectra and side-effect profiles [1]. $\beta$-lactam antibiotics are the most commonly prescribed antimicrobial in both the hospital and community settings and remain one of the safest antimicrobials prescribed [2]. Additionally, in the livestock industry, $\beta$-lactam antibiotics have been widely used in animal production for chemotherapeutic growth promoters and infectious diseases treatments such as mastitis and pneumonia [3]. In aquaculture, many antibiotics are allowed for use in aquaculture as $\beta$-lactam antibiotics worldwide. Antibiotics in aquaculture are administered through the feed or culture water. Therefore, there can be accumulation of antibiotics in water and sediments which can contaminate the aquatic ecosystem. In addition, some antibiotics from intensive livestock can also be released into the environment and reach water resources [4]. In Taiwan, the use of antibiotics in the aquaculture is more valued. Therefore, there are only 14 antibiotics as amoxicillin, ampicillin etc. allowed in the Taiwan aquaculture by Taiwan government.

Antibiotics are frequently used to protect livestock from bacterial diseases, therefore, antibiotic resistance is very important widespread. At present, extensive antibiotic resistant strains are now being detected and the development of antibiotic-resistant strains of epidemic and zoonotic pathogens is now a major concern. About $75 \%$ of emerging infectious diseases in humans have been reported to originate from zoonotic pathogens. Aquaculture systems contain lots numbers of diverse bacteria that exist in combination with the current and past use of antibiotic treatment regimens. Fish are reservoirs of zoonotic pathogens that cannot only infect the animal host but can also infect humans. These genetic hotspots of aquaculture are the production sites of antibiotic resistant strains via gene transfer. As the human population increases there is an increasing reliance on aquaculture to supply a safe, reliable, and economic supply of food. Antibiotic resistant problems in aquaculture is more concerned $[5,6]$.

Drugs residues in the tissues and milk of animal pose a potential threat to human health. There is an obvious need for rapid and accurate method for measuring drug residues in these biomatrix in order to protect consumers' health. Many techniques currently are used to analyze drug residues, including immuno-diffusion, chemical analysis, gel-filtration chromatography, ultracentrifugation, electrophoresis, and isotope labeling analysis. Omura et al. reported that high performance liquid chromatography (HPLC) with mass spectrometry and proton nuclear magnetic resonance $\left({ }^{1} \mathrm{H}-\mathrm{NMR}\right)$ detector can be efficacious in sorting productive component, 2'-deoxycytidine. Duan and Yuan used sodium dodecyl sulfate polyacrylamide gel electrophoresis (SDS-PAGE), $\mathrm{FeCl}_{3} \mathrm{colorimetry}$ and ultraviolet/visible (UV/VIS) scanning methods to ensure the ciprofloxacin-bovine serum albumin (BSA) conjugate was complete $[7,8]$. The method was able to detect the conjugate but the technique was very complicated and expensive to perform. Hung et al. reported that detection of the conjugation of fluoroquinolones and BSA by HPLC with UV and fluorescence detectors, the method was a rapid and accurate method to understand the conjugation degree and the production of the conjugates [9]. Taken together, we hope to develop the cheaper, simpler, rapid, and accurate methods to produce and detect $\beta$-lactam antibiotic-serum albumin (SA) conjugates.

The SA are the major abundant proteins in the human and animals and contribute to the osmotic blood pressure, which play a dominant role in drug disposition and efficacy [10]. Many drugs can bind reversibly to albumin, which then function as carriers. SA often increases the apparent solubility of hydrophobic drugs in plasma and modulate their delivery to cells. Furthermore, antibiotics are belonged to haptens that molecule weight (MW) is too small to produce antibodies. When haptens conjugated with SA, high MW of the conjugates is enlarged to produce hapten antibodies [11]. Therefore, understand of the conjugation of $\beta$-lactam antibiotics and SA will be favorable for antibody production in the future.

$\beta$-lactam antibiotics represented the oldest class of antibiotics used in the treatment of infections and were generally available for parenteral application and widely used in clinical practice [12]. Antibiotics are belonged to haptens that molecule weight (MW) is too small to produce antibodies. When haptens conjugated with SA, high MW of the conjugates is enlarged to produce hapten antibodies [6,11]. These antibiotics are low MW structures and the immunological responses are still an exciting area of investigation. $\beta$-lactam antibiotics were able to interact covalently with serum proteins and formed immunogenic conjugates to provoke a number of different antigenic determinants that have been implicated in the specificity of the immunological response [13]. Therefore, understand of the conjugation of $\beta$-lactam antibiotics and SA will be favorable for antibody production in the future. In this study, the purpose of this study was to estimate the extent of $\beta$-lactam antibiotics-HSA/BSA conjugations via three conjugation methods by using HPLC with UV detector.

\section{Materials and Methods}

\section{Chemicals}

In this study, three $\beta$-lactam antibiotics, amoxicillin (AMX, Pfizer, New York, NY, USA), ampicillin (AM, Bayer, Wuppertal Germany), and penicillin G (PG, Sigma-Aldrich, Louis, MO, USA) were used. Human serum albumin (HSA), bovine serum albumin (BSA), glutaraldehyde, and pentobarbituric acid were also purchased from Sigma-Aldrich (Figure 1A,1B and 1C).

\section{Apparatus and detection conditions}

The HPLC system consisted of a LC1022 Plus (Perkin-Elmer, Bridgeport, CT, USA), Degasys DG-1210 (Uniflows, Tokyo, Japan), a chromatointegrator (PE Nelson 1022; Perkin-Elmer), Cosmosil 5C18-AR-300 column (4.6 250 mm, Nacalai, Kyoto, Japan), and an UV detector 
that was set the wavelength of $210 \mathrm{~nm}$ (LC295) (Perkin-Elmer, Bridgeport, CT, USA) [14]. Analysis was performed by a chromatointegrator (PE Nelson 1022; Perkin-Elmer).

A

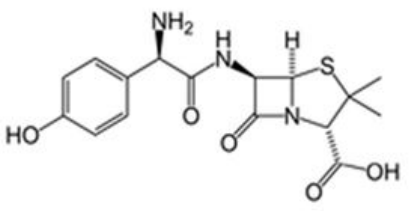

B<smiles>CC1(C)S[C@@H](NC(=O)[C@H](N)c2ccccc2)C(=O)N1C(=O)O</smiles>

C<smiles>CC1(C)SC2C(NC(=O)Cc3ccccc3)C(=O)N2C1C(=O)O</smiles>

D<smiles>CC(C)N1NC(C(=O)O)C(NC(=O)C(N)(c2ccccc2)c2ccccc2)C1C</smiles>

E

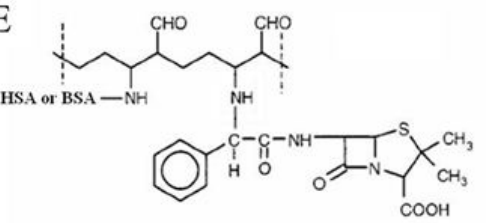

F

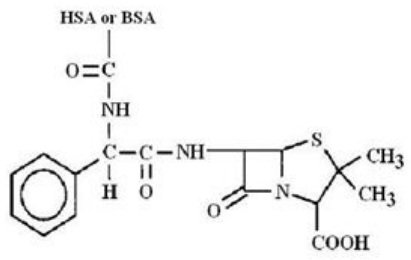

Figure 1: The structures of three $\beta$-lactam antibiotics and conjugated methods with HSA or BSA. A. amoxicillin; B. ampicillin; C. penicillin G; D. ampicillin-HSA or BSA conjugate via physiological coupling method; E. ampicillin-HSA or BSA conjugate via glutaraldehyde coupling method; F. ampicillin-HSA or BSA conjugate via carbodiimide-mediated coupling method

\section{Preparation of $\beta$-lactam antibiotics-HSA/BSA conjugates}

A modified version of the method described by Cliquet et al., Dietrich et al., and Samsonva et al. were used [15-17]. The haptens, namely amoxicillin (AMX), ampicillin (AM), and penicillin G (PG), were respectively conjugated with the carrier proteins, HSA or BSA, by the physiological coupling method (PCM), glutaraldehyde-mediated coupling method (GCM), and carbodiimide-mediated coupling method (CCM) (Figure 1D,1E and 1F).

Three conjugated methods (CCM, GCM, and PCM) were performed. CCM was followed as $415 \mu \mathrm{M}$ of each $\beta$-lactam antibiotics, 1-ethyl-3-(3dimethylaminopropyl)-carbodiimide, and $4.15 \mu \mathrm{M}$ HSA/BSA were dissolved into $\mathrm{pH} 6.0$ triple distilled water (10 mL). The mixture solution respectively was stirred at room temperature in the dark for $2 \mathrm{hr}$, then incubated at $4 \mu \mathrm{C}$ for $14 \mathrm{hr}$. Finally, the solution was dialyzed with $0.01 \mathrm{M}$ phosphate buffer saline (PBS, pH 7.4) at $4{ }^{\circ} \mathrm{C}$ for six days; GCM was followed as $40 \mathrm{mg}$ of each $\beta$-lactam antibiotics and $40 \mathrm{mg}$ HSA/BSA were dissolved into $0.01 \mathrm{M}, \mathrm{pH}$ 6.5 PBS $(10 \mathrm{~mL})$, then $200 \mu \mathrm{L}, 25 \%$ glutaraldehyde solution was added into the above solution and stirred at room temperature in the dark for $6 \mathrm{hr}$. Finally, the solution was dialyzed with $0.01 \mathrm{M} \mathrm{PBS}\left(\mathrm{pH} 7.4\right.$ ) at $4{ }^{\circ} \mathrm{C}$ for six days; PCM was followed as $1.0 \mathrm{~g}$ of each $\beta$-lactam antibiotics and $0.25 \mathrm{~g} \mathrm{HSA} / \mathrm{BSA}$ were dissolved into $0.008 \mathrm{M}, \mathrm{pH} 8.5$ pentobarbituric acid $(10 \mathrm{~mL})$ at $37^{\circ} \mathrm{C}$ for $24 \mathrm{hr}$, then the solution was dialyzed with $0.01 \mathrm{M}$ PBS ( $\mathrm{pH}$ 7.4) at $4 \mu \mathrm{C}$ for six days [15-17]. Finally, these conjugates were determined the protein concentrations by using the Coomassie plus protein assay reagent kit (Pierce, Rockford, IL, USA). These conjugates were condensed with the Speed Vac SC 110-120 (Savant, Holbrook, NY, USA) and stored at $-80^{\circ} \mathrm{C}$ until use.

\section{Detection of the $\beta$-lactam antibiotics-HSA/BSA conjugates}

SA (HSA and BSA), $\beta$-lactam antibiotics (AMX, AM, and PG), and conjugates were diluted with PBS to form $1 \mathrm{mg} / \mathrm{mL}$. A volume of $20 \mu \mathrm{L}$ of each was injected into the HPLC system. First, the mobile phase was depleted of gas using Degasys DG-1210, which included 100\% acetonitrile with $0.05 \%$ trifluoracetic acid (TFA) (Baker, Phillipsburg, NJ, USA) and $5 \mathrm{mM}, \mathrm{pH} 6.5 \mathrm{KH}_{2} \mathrm{PO}_{4}$ at a ratio of $40: 60$ (v/v). The $\beta$-lactam antibiotics-HSA conjugates solutions were transported with LC1022 Plus and separated with a Cosmosil 5C18-AR-300 column $(4.6 \times 250 \mathrm{~mm})($ Nacalai, Kyoto, Japan). The flow rate in our analysis system was $0.4 \mathrm{~mL} / \mathrm{min}$ for HSA-related products and $0.6 \mathrm{~mL} / \mathrm{min}$ for BSA-related products. The wavelength of $210 \mathrm{~nm}$ in UV detector was set to detect the $\beta$-lactam antibiotics [14], HSA/BSA, and $\beta$-lactam antibiotics-HSA/BSA conjugates. Additionally, a chromatointegrator was used in the analyses of the data.

\section{Statistical analysis}

Experiments were conducted in triplicate. Mean \pm SD was calculated, and statistical analysis was performed using Excel student's $t$-test.

\section{Results}

First, $0.5 \mathrm{mg} / \mathrm{mL}$ BSA or HSA $(20 \mu \mathrm{L})$ was respectively injected into the HPLC system and the obvious peak time of BSA or HSA was detected via ultraviolet detector. Results showed an obvious peak of BSA or HSA at 4.280 or 8.637 min under the UV detector, respectively (BSA in Figures 2A, 3A, 4A; HSA in Figures 5A, 6A, 7A). $0.1 \mathrm{mg} / \mathrm{mL}(20 \mu \mathrm{L})$ each of AMX, AM, and PG were respectively injected and detected via HPLC with 
UV detector. Results revealed that there were obvious peaks of AMX respectively at 5.057 min (Figure 2B) and 7.703 min (Figure 5B); AM peaks were at $6.920 \mathrm{~min}$ (Figure 3B) and $8.777 \mathrm{~min}$ (Figure 6B), respectively; PG peaks were respectively at 9.160 min (Figure 4B) and 7.943 min (Figure 7B).

In addition, we have detected AMX-BSA conjugates $(20 \mu \mathrm{L})$ that conjugated respectively via CCM, GCM, and PCM. Results showed that there were obvious peaks of AMX-BSA conjugates at 5.863, 5.810, and $5.783 \mathrm{~min}$, respectively (Figures 2B-D); detection of AM-BSA conjugates (20 $\mu \mathrm{L}$ ) that respectively conjugated via CCM, GCM, and PCM. Results showed there were obvious peaks of AM-BSA conjugates at 5.773, 5.813, and $5.813 \mathrm{~min}$, respectively (Figures 3B-D); detection of PG-BSA conjugate $(20 \mu \mathrm{L})$ that respectively conjugated via CCM, GCM, and PCM. Results showed there were obvious peaks of PG-BSA conjugates at 5.827, 5.750, and $5.840 \mathrm{~min}$, respectively (Figures 4B-D).
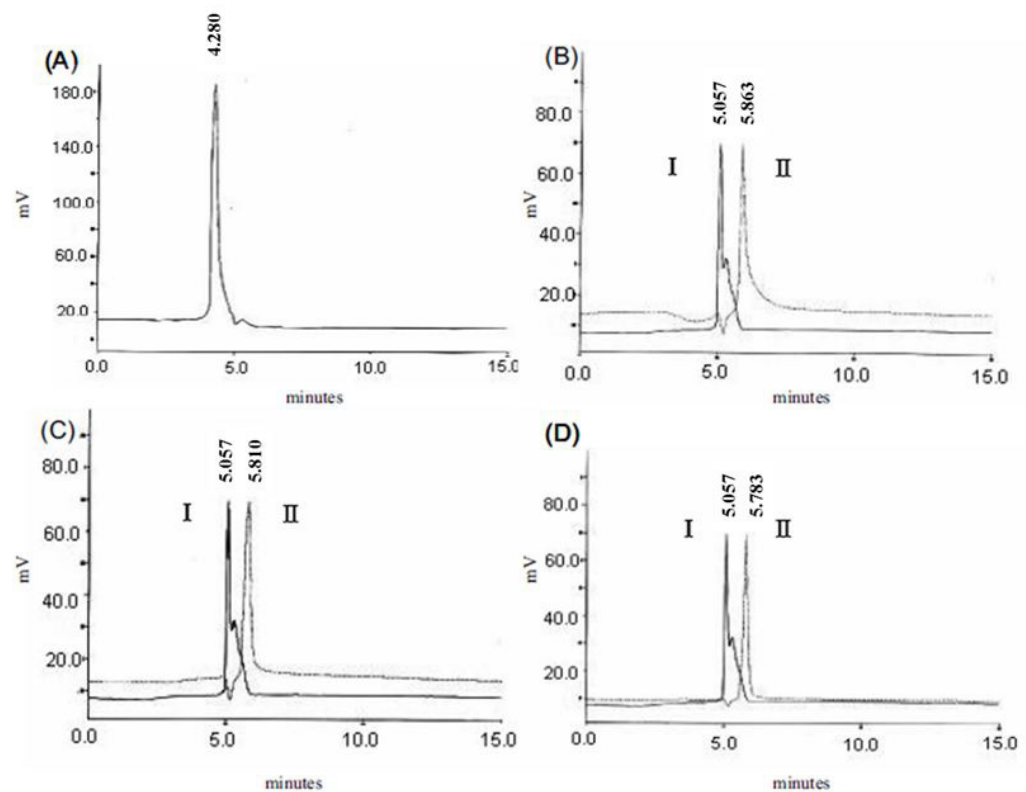

Figure 2: Bovine serum albumin (BSA), amoxicillin (AMX), and AMX-BSA conjugate were detected using HPLC with ultraviolet detector. A. $0.5 \mathrm{mg} / \mathrm{mL}$ BSA alone; B. $0.5 \mathrm{mg} /$ $\mathrm{mL}$ BSA, $0.1 \mathrm{mg} / \mathrm{mL} \mathrm{AMX}$, and $0.4 \mathrm{mg} / \mathrm{mL}$ AMX-BSA conjugate ${ }^{\mathrm{II}}$ with the carbodiimidemediated coupling method; C. $0.5 \mathrm{mg} / \mathrm{mL}$ BSA, $0.1 \mathrm{mg} / \mathrm{mL}$ AMX', and $0.4 \mathrm{mg} / \mathrm{mL}$ AMX-BSA

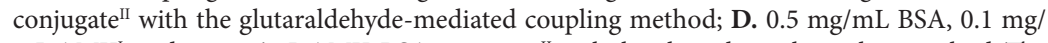
$\mathrm{mL} \mathrm{AMX}^{\mathrm{I}}$, and $0.4 \mathrm{mg} / \mathrm{mL}$ AMX-BSA conjugate ${ }^{\mathrm{II}}$ with the physiological coupling method. The experiments was performed is in triplicate
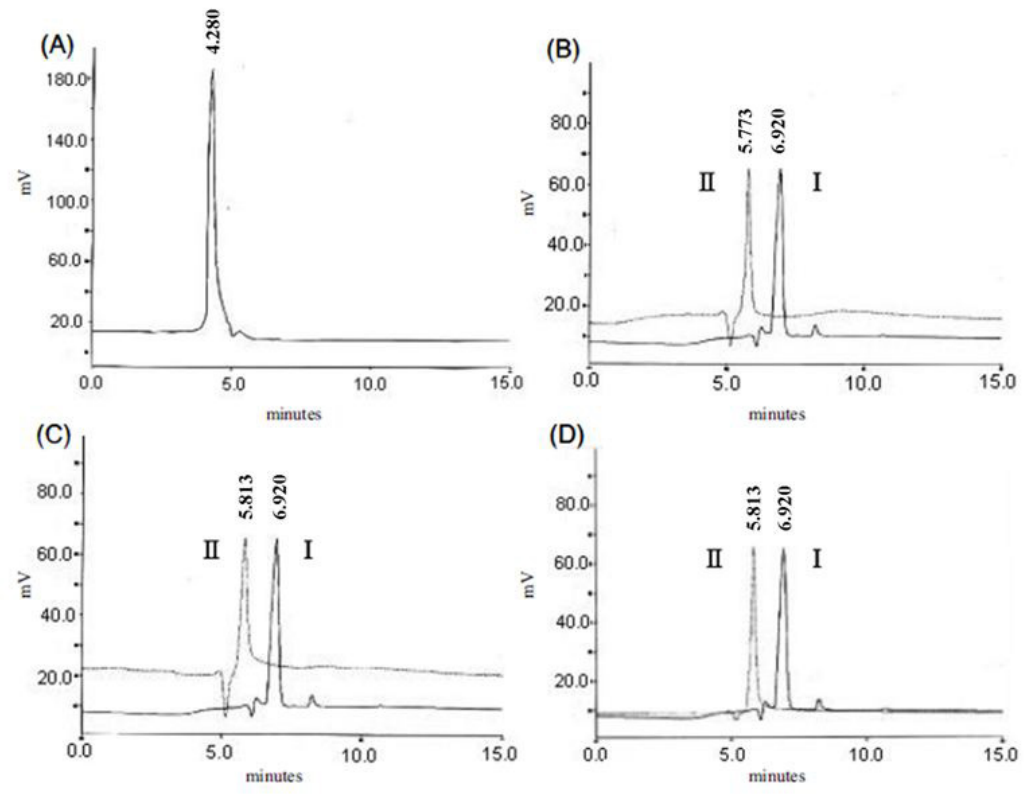

Figure 3: Bovine serum albumin (BSA), ampicillin (AM), and AM-BSA conjugate were detected using HPLC with ultraviolet detector. A. $0.5 \mathrm{mg} / \mathrm{mL}$ BSA alone; B. $0.5 \mathrm{mg} / \mathrm{mL}$ BSA, $0.1 \mathrm{mg} / \mathrm{mL} \mathrm{AM}$, and $0.4 \mathrm{mg} / \mathrm{mL}$ AM-BSA conjugate ${ }^{\mathrm{II}}$ with the carbodiimide-mediated coupling method; C. $0.5 \mathrm{mg} / \mathrm{mL}$ BSA, $0.1 \mathrm{mg} / \mathrm{mL} \mathrm{AM}^{\mathrm{I}}$, and $0.4 \mathrm{mg} / \mathrm{mL}$ AM-BSA conjugate ${ }^{\mathrm{II}}$ with the glutaraldehyde-mediated coupling method; $\mathbf{D} .0 .5 \mathrm{mg} / \mathrm{mL} \mathrm{BSA}, 0.1 \mathrm{mg} / \mathrm{mL} \mathrm{AM}^{\mathrm{I}}$, and $0.4 \mathrm{mg} / \mathrm{mL}$ AM-BSA conjugate ${ }^{\mathrm{II}}$ with the physiological coupling method. The experiments was performed is in triplicate 

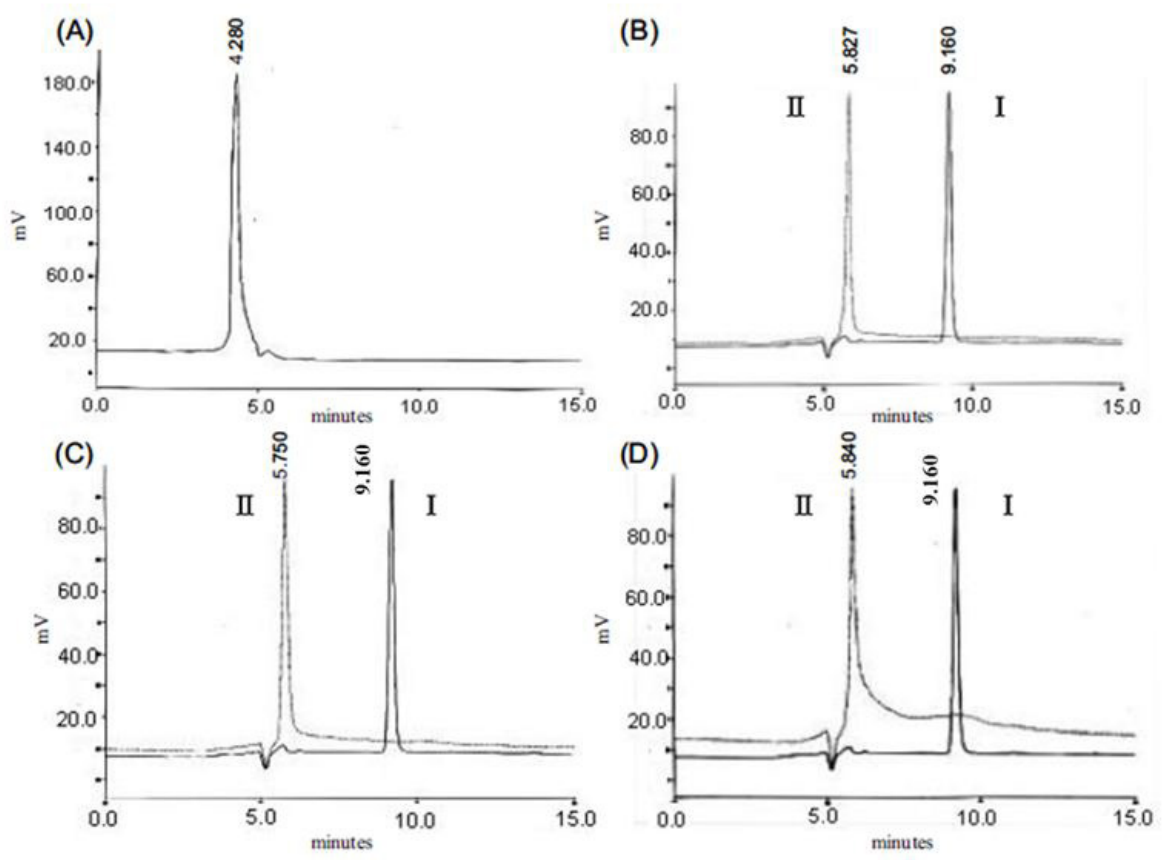

Figure 4: Bovine serum albumin (BSA), penicillin G (PG), and PG-BSA conjugate were detected using HPLC with ultraviolet detector. A. $0.5 \mathrm{mg} / \mathrm{mL}$ BSA alone; B. $0.5 \mathrm{mg} / \mathrm{mL} \mathrm{BSA}, 0.1 \mathrm{mg} / \mathrm{mL} \mathrm{PG}^{\mathrm{I}}$, and $0.4 \mathrm{mg} /$ $\mathrm{mL}$ PG-BSA conjugate ${ }^{\mathrm{II}}$ with the carbodiimide-mediated coupling method; C. $0.5 \mathrm{mg} / \mathrm{mL} \mathrm{BSA}, 0.1 \mathrm{mg} / \mathrm{mL}$ $\mathrm{PG}^{\mathrm{I}}$, and $0.4 \mathrm{mg} / \mathrm{mL}$ PG-BSA conjugate ${ }^{\mathrm{II}}$ with the glutaraldehyde-mediated coupling method; D. $0.5 \mathrm{mg} /$ $\mathrm{mL}$ BSA, $0.1 \mathrm{mg} / \mathrm{mL} \mathrm{PG}^{\mathrm{I}}$, and $0.4 \mathrm{mg} / \mathrm{mL}$ PG-BSA conjugate ${ }^{\mathrm{II}}$ with the physiological coupling method. The experiments was performed is in triplicate

Moreover, we also detected AMX-HSA conjugates $(20 \mu \mathrm{L})$ that conjugated respectively via CCM, GCM, and PCM. The obvious peaks of AMXHSA conjugates at 7.230, 7.370, and 10.690 min were found, respectively (Figures 5B-D); detection of AM-HSA conjugates (20 $\mu \mathrm{L}$ ) that conjugated respectively via CCM, GCM, and PCM. The peaks of AM-HSA conjugate at 5.833, 8.067, and 9.723 min were found, respectively (Figures 6B-D); detection of PG-HSA conjugates $(20 \mu \mathrm{L})$ that conjugated respectively via CCM, GCM, and PCM. The obvious peaks of PG-HSA conjugates at 7.237, 7.197, and 10.423 min were found, respectively (Figures 7B-D).

$$
\text { (A) }
$$

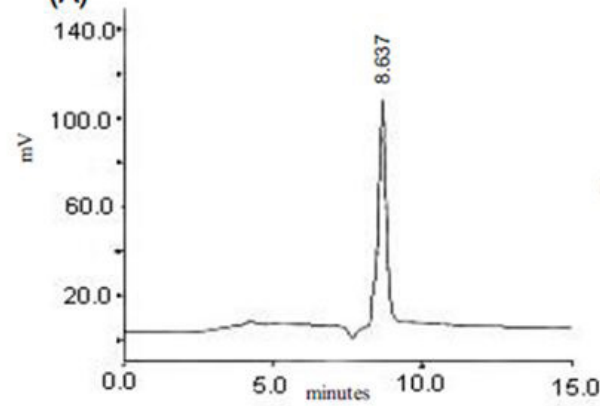

(C)

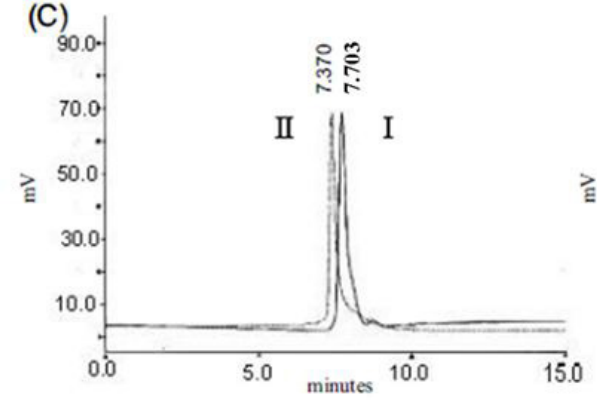

(B)
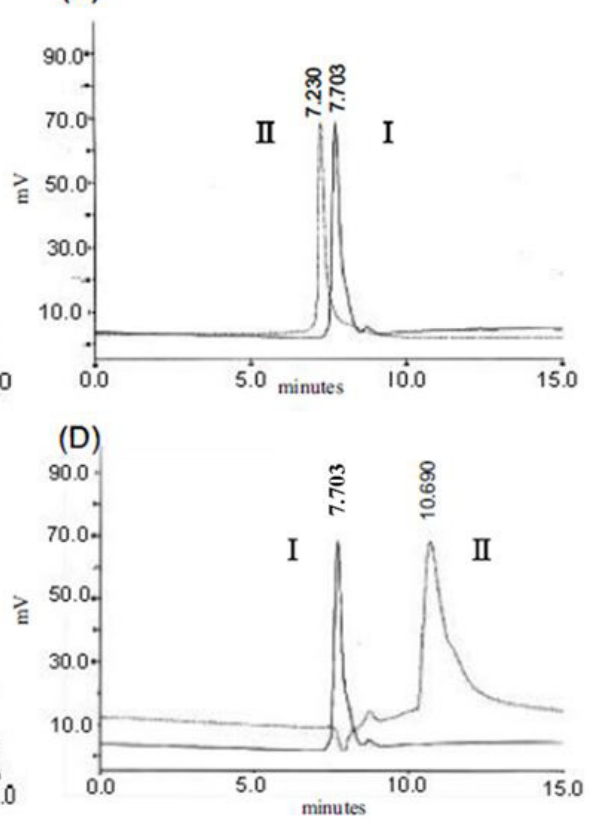

Figure 5: Human serum albumin (HSA), amoxicillin (AMX), and AMX-HSA conjugate were detected using HPLC with ultraviolet detector. A. $0.5 \mathrm{mg} / \mathrm{mL}$ HSA alone; B. $0.5 \mathrm{mg} / \mathrm{mL}$ HSA, $0.1 \mathrm{mg} / \mathrm{mL} \mathrm{AMX}^{\mathrm{I}}$, and 0.4 $\mathrm{mg} / \mathrm{mL}$ AMX-HSA conjugate ${ }^{\mathrm{II}}$ with the carbodiimide-mediated coupling method; C. $0.5 \mathrm{mg} / \mathrm{mL}$ HSA, 0.1 $\mathrm{mg} / \mathrm{mL} \mathrm{AMX}^{\mathrm{I}}$, and $0.4 \mathrm{mg} / \mathrm{mL}$ AMX-HSA conjugate ${ }^{\mathrm{II}}$ with the glutaraldehyde-mediated coupling method; D. $0.5 \mathrm{mg} / \mathrm{mL} \mathrm{HSA}, 0.1 \mathrm{mg} / \mathrm{mL}$ AMX, and $0.4 \mathrm{mg} / \mathrm{mL}$ AMX-HSA conjugate ${ }^{\mathrm{II}}$ with the physiological coupling method. The experiments was performed is in triplicate 

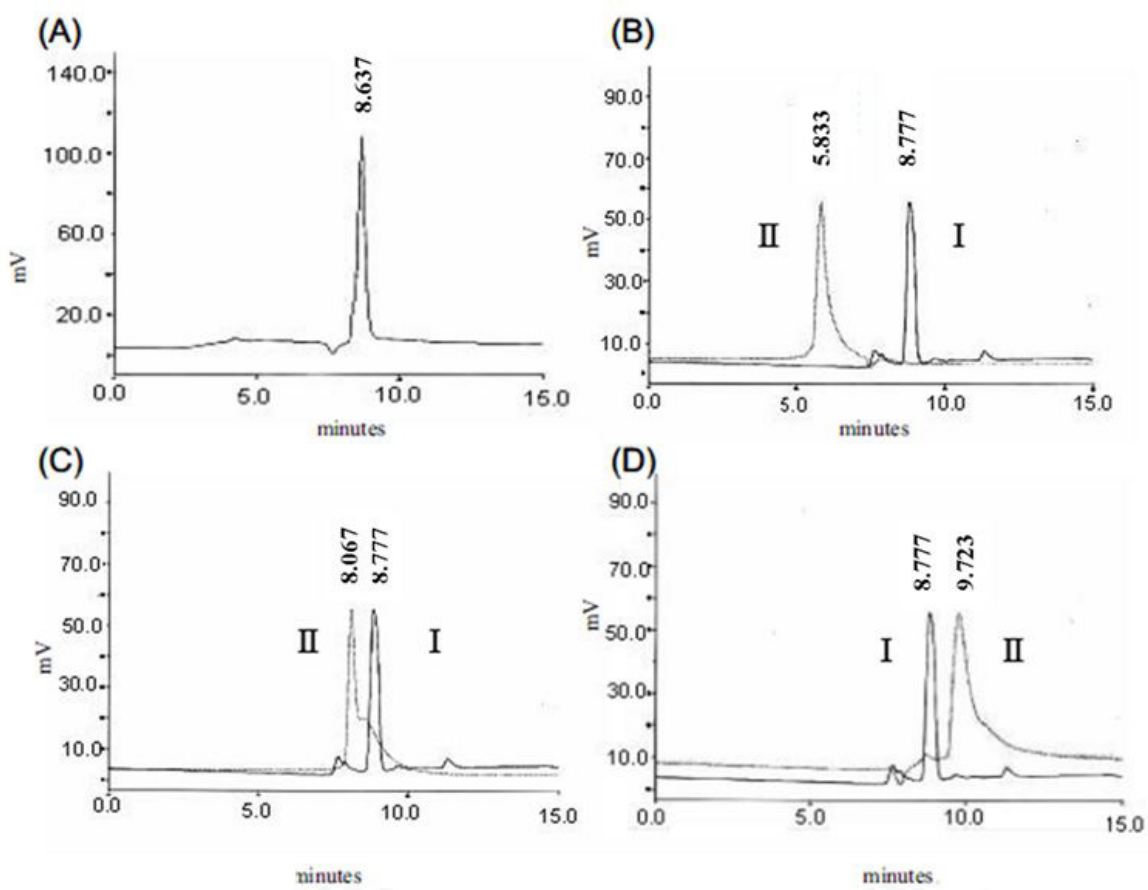

Figure 6: Human serum albumin (HSA), ampicillin (AM), and AM-HSA conjugate were detected using HPLC with ultraviolet detector. A. $0.5 \mathrm{mg} / \mathrm{mL}$ HSA alone; B. $0.5 \mathrm{mg} / \mathrm{mL}$ HSA, $0.1 \mathrm{mg} / \mathrm{mL} \mathrm{AM}^{\mathrm{I}}$, and 0.4 $\mathrm{mg} / \mathrm{mL}$ AM-HSA conjugate ${ }^{\mathrm{II}}$ with the carbodiimide-mediated coupling method; C. $0.5 \mathrm{mg} / \mathrm{mL}$ HSA, 0.1 $\mathrm{mg} / \mathrm{mL} \mathrm{AM}$, and $0.4 \mathrm{mg} / \mathrm{mL}$ AM-HSA conjugate ${ }^{\mathrm{II}}$ with the glutaraldehyde-mediated coupling method; $\mathbf{D}$. $0.5 \mathrm{mg} / \mathrm{mL} \mathrm{HSA}, 0.1 \mathrm{mg} / \mathrm{mL} \mathrm{AM}$, and $0.4 \mathrm{mg} / \mathrm{mL}$ AM-HSA conjugate ${ }^{\mathrm{II}}$ with the physiological coupling method. The experiments was performed is in triplicate
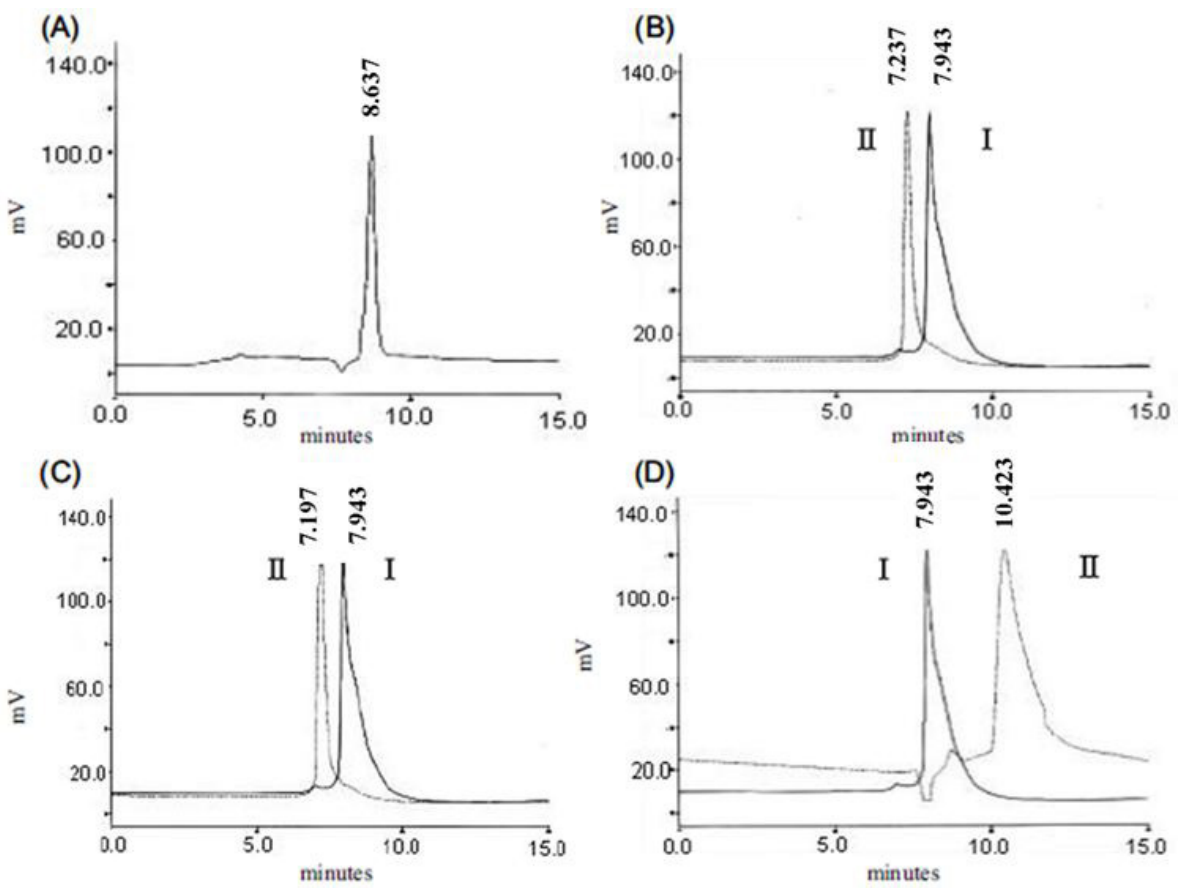

Figure 7: Human serum albumin (HSA), penicillin G (PG), and PG-HSA conjugate were detected using HPLC with ultraviolet detector. A. $0.5 \mathrm{mg} / \mathrm{mL}$ HSA alone; B. $0.5 \mathrm{mg} / \mathrm{mL}$ HSA, $0.1 \mathrm{mg} / \mathrm{mL} \mathrm{PG}^{\mathrm{I}}$, and $0.4 \mathrm{mg} /$ $\mathrm{mL}$ PG-HSA conjugate ${ }^{\mathrm{II}}$ with the carbodiimide-mediated coupling method; C. $0.5 \mathrm{mg} / \mathrm{mL} \mathrm{HSA}, 0.1 \mathrm{mg} / \mathrm{mL}$ $\mathrm{PG}^{\mathrm{I}}$, and $0.4 \mathrm{mg} / \mathrm{mL}$ PG-HSA conjugate ${ }^{\mathrm{II}}$ with the glutaraldehyde-mediated coupling method; D. $0.5 \mathrm{mg} /$ $\mathrm{mL}$ HSA, $0.1 \mathrm{mg} / \mathrm{mL} \mathrm{PG}^{\mathrm{I}}$, and $0.4 \mathrm{mg} / \mathrm{mL}$ PG-HSA conjugate ${ }^{\mathrm{II}}$ with the physiological coupling method. The experiments was performed is in triplicate

The obvious peaks of these conjugates were obviously separated from BSA or HSA. Furthermore, no other peaks of proteins were observed during the conjugates detection. Thus, $\beta$-lactam antibiotics (AMX, AM, and PG) and SA (HSA and BSA) conjugation based on three conjugated methods, CCM, GCM, and PCM and detection method, HPLC with UV detector, were able to successfully detect $\beta$-lactam antibiotics-SA conjugates. 


\section{Discussion}

Recently, the recognition and binding of $\beta$-lactam antibiotics to SA may be one of the most concerned issues for people. Recognition and binding of $\beta$-lactam antibiotics to biomacromolecules as SA have high interest in both academic and industrial life science research. This information can not only provide the useful data on the pharmacologics of $\beta$-lactam antibiotics in the body, but also illustrate some new insights for the innovative clinical medication and new $\beta$-lactam antibiotics design with special pharmacological property [18].

$\beta$-lactam antibiotics, such as AMX, AM, PG, cefoperazone, and cefotaxime, are widely used for the treatment of bacterial infections in human and animals [19]. Additionally, antibiotics are applied in the livestock and aquaculture must be careful because their wide application in animals represents a potentialhazard that residues of these antibiotics may persist in edible tissues or foodstuffs. Therefore, development of a simple, rapid, reliable, and economical technique for the detection of $\beta$-lactam antibiotics-SA conjugates was need. Especially, the technique will be applied in the livestock and aquaculture farms in clinical.

SA is the most abundant proteins in blood plasma and act as the main carriers in the blood circulatory system. Thus, their ligands included drugs, fatty acids, hormones and other biological active compounds in the body [18]. Currently, BSA has become one of the most extensively used proteins in evaluating the interactions between drugs and proteins due to its water solubility, versatile binding ability, functional properties and structural homology (80\%) with HSA [19-21]. It has been reported that the effect of the same kind of drugs such as antibiotics showed very similar binding properties with BSA and HSA [22-23]. In this work, both BSA and HSA were respectively used as the conjugated proteins for $\beta$-lactam antibiotics-SA interaction study, which could provide the valuable references for the interaction of $\beta$-lactam antibiotics and HSA/BSA, respectively.

Several methods have been developed for the determination of $\beta$-lactam antibiotics in edible tissues or foodstuffs [18]. In this study, the conjugation of $\beta$-lactam antibiotics (AMX, AM, and PG) with HSA/BSA was successfully established by PCM, GCM, and CCM, respectively. These conjugates were analyzed by using HPLC with UV detector. Compared with the method employed by Duan and Yuan, Decroix et al., and Mayorga et al., our modified technique was easier and cheaper to use for detecting $\beta$-lactam antibiotics-HSA/BSA conjugates and estimating the degree of conjugation according to integrated areas $[8,24,25]$. According to the degree of conjugation, we could understand whether $\beta$-lactam antibiotics-HSA/BSA conjugation were already accomplished.

Antibiotics residues in edible tissues or foodstuffs is a very serious issue that was cornered with public health concerns. Because $\beta$-lactam antibiotics are haptens, they must be conjugated with high MW carrier proteins to induce the production of anti-beta-lactam antibiotics antibodies [26]. Therefore, a detection method for the conjugation of $\beta$-lactam antibiotics and SA during the combination stage is needed. Wang et al. reported that the determination of ampicillin sodium in the presence of HSA with spectrofluorometer was a sensitive and selective method [27]. The maximum emission wavelength of ampicillin sodium was at $426 \mathrm{~nm}$ with excitation at $254 \mathrm{~nm}$. Determination of ampicillin and ampicillin-BSA with GCM via its absorbance at $280 \mathrm{~nm}$ and defined the coupling efficiency using the bicinchoninic acid assay [15,28]. Duan and Yuan indicated that the absorption wavelength for ciprofloxacin-BSA and BSA was $271 \mathrm{~nm}$ and $275 \mathrm{~nm}$, respectively. Pauillac et al. revealed that the wavelength of 200 to $300 \mathrm{~nm}$ in UV detector was suitable for the hapten (4-acetyl benzoic acid) and carrier protein (BSA) [8,29]. Their results were showed that 4-acetyl benzoic acid had an absorption wavelength among 210 and $254 \mathrm{~nm}$ while BSA had an absorption wavelength between 210 and $280 \mathrm{~nm}$. Hung et al. reported that the wavelength of $280 \mathrm{~nm}$ in UV detector and the excitation wavelength of $290 \mathrm{~nm}$ and an emission wavelength of $450 \mathrm{~nm}$ in fluorescence detector were used to detect the conjugation of fluoroquinolones and BSA [9]. In the present study, our results presented that the appropriate absorption wavelength of UV detector was $210 \mathrm{~nm}$ for three $\beta$-lactam antibiotics (AMX, AM, and PG), $\beta$-lactam antibiotics-SA conjugates, and SA.

Antibiotics are used to prevent and treat bacterial infections in human being and animals. Antibiotic resistance occurs when bacteria change in response to the use of these medicines. These antibiotic-resistant bacteria may infect humans and animals, and the infections they cause are harder to treat than those caused by non-resistant bacteria. Antibiotic resistance leads to higher medical costs, prolonged hospital stays, and increased mortality in human being, livestock, and aquaculture. The world urgently needs to change the way it prescribes and uses antibiotics. Even if new medicines are developed, antibiotic resistance will remain a major threat. In this study, a simple, rapid, and reliable technique was established to detect $\beta$-lactam antibiotics-conjugated SA. The developed technique may be a valuable tool for the detection of drug-carrier conjugated antigens, especially for three $\beta$-lactam antibiotics-SA conjugates. We hope that the technique will be applied to preliminarily detect the residues of $\beta$-lactam antibiotics may persist in edible tissues or foodstuffs in the livestock and aquaculture farms in clinical.

\section{Conflicts of interest}

All authors declare no conflicts of interest.

\section{Acknowledgments}

We would like to thank the Council of Agriculture, Executive Yuan, Taiwan, for its financial support [91AS-1.2.2-BQ-B2 and 92AS-3.3.1BQ-B1(1)].

\section{References}

1. Fernandes R, Amador P, Prudêncio C (2013) $\beta$-Lactams: chemical structure, mode of action and mechanisms of resistance. Rev Med Microbiol 24: 7-17.

2. Prestinaci F, Pezzotti P, Pantosti A (2015) Antimicrobial resistance: a global multifaceted phenomenon. Pathog Glob Health 109: $309-18$.

3. Rezende CP, Almeida MP, Brito RB, Nonaka CK, Leite MO (2012) Optimisation and validation of a quantitative and confirmatory LC-MS method for multiresidue analyses of $\beta$-lactam and tetracycline antibiotics in bovine muscle. Food Addit Contam Part A Chem Anal Control Expo Risk Assess 29: 541-9. 
4. Guidi LR, Santos FA, Ribeiro AC, Fernandes C, Silva LH, et al. (2017) A simple, fast and sensitive screening LC-ESI-MS/MS method for antibiotics in fish. Talanta 163: 85-93.

5. Shahid N, Daniell H (2016) Plant-based oral vaccines against zoonotic and non-zoonotic diseases. Plant Biotechnol J 14: $2079-99$.

6. Watts JEM, Schreier HJ, Lanska L, Hale MS (2017) The rising tide of antimicrobial Resistance in aquaculture: sources, sinks and solutions. Mar Drugs 15: 158.

7. Omura K, Hirose K, Itoh M, Akizawa T, Yoshioka M (1997) Development of enzyme immunoassay of 2'-deoxycytidine. J Pharm Biomed Anal 15: 1249-56.

8. Duan J, Yuan Z (2001) Development of an indirect competitive ELISA for ciprofloxacin residues in food animal edible tissues. J Agric Food Chem 49: 1087-9.

9. Hung SW, Shih CW, Chen PR, Tu CY, Ho SP, et al. (2007) Development of detecting the conjugation of fluoroquinolones and bovine serum albumin by highperformance liquid chromatography to detect. J Food Drug Anal 15: 71-4.

10. Guo M, Zou JW, Yi PG, Shang ZC, Hu GX, et al. (2004) Bind interaction of gatifloxacin with bovine serum albumin. Anal Sci 20: 465-70.

11. Kamat BP (2005) Study of the interaction between fluoroquinolones and bovine serum albumin. J Pharm Biomed Anal 39: 1046-50.

12. Bergan T (1984) Pharmacokinetics of beta-lactam antibiotics. Scand J Infect Dis Suppl 42: 83-98.

13. Atsumi T, Nishida K, Kinoshida Y, Shibata K, Horiuchi Y (1967) The heterogeneity of combining sites of antibenzylpeniciloyl antibodies obtained from individual rabbits: fractionation of antibodies with a specific immunoadsorbent. J Immunol 99: 1286-93.

14. Hung SW, Tsai YC, Ho SP, Tu CY, Wang SL, et al. (2005) A study for amoxicillin residue detection technique. Taiwan Vet J 31: 46-55.

15. Cliquet P, Cox E, Van Dorpe C, Schacht E, Goddeeris BM (2001) Generation of class-selective monoclonal antibodies against the penicillin group. J Agric Food Chem 49: 3349-55.

16. Dietrich R, Usleber E, Martlbauer E (1998) The potential of monoclonal antibodies against ampicillin for the preparation of a multi-immunoaffinity chromatography for penicillins. Analyst 123: 2749-54.

17. Samsonova ZHV, Shchelokova OS, Ivanova NL, Rubtsova MY, Egorov AM (2005) Enzyme-linked immunosorbent assay of ampicillin in milk. Appl Biochem Microbiol 41: 589-95.

18. Li Q, Zhang T, Bian L (2016) Recognition and binding of $\beta$-lactam antibiotics to bovine serum albumin by frontal affinity chromatography in combination with spectroscopy and molecular docking. J Chromatogr B Analyt Technol Biomed Life Sci 1014: 90-101.

19. Li JH, Wang SM (2013) Molecular spectroscopic on interaction between methylhesperidin and buman serum albumin, Spectrochim. Acta Part A 102: 200-4.

20. Guo XJ, Sun XD, Xu SK (2009) Spectroscopic investigation of the interactionbetween riboflavin and bovine serum albumin. J Mol Struct 931: 55-9.

21. Rajendiran N, Thulasidhasan J (2015) Interaction of sulfanilamide andsulfamethoxazole with bovine serum albumin and adenine: spectroscopic andmolecular docking investigations. Spectrochim Acta A 144: 183-91.

22. Keswani N, Choudhary S, Kishore N (2010) Interaction of weakly bound antibioticsneomycin and lincomycin with bovine and human serum albumin: biophysical approach. J Biochem 148: 71-84.

23. Mukherjee M, Sardar PS, Ghorai SK, Samanta SK, Roy AS, et al. (2013) A comparative study of interaction of tetracycline with severalproteins using time resolved anisotropy, phosphorescence, docking and FRET. PLoS One 8: e60940.

24. Decroix MO, Chaumeil JC, Flouvat B (1984) Binding of cefalotin to human serum albumin. Eur J Drug Metab Pharmacokinet 9: $191-4$.

25. Mayorga C, Torres MJ, Romano A, Moreno F, Sanchez-Sabater E, et al. (2002) Monoclonal antibodies to amoxicillin express different idiotypes determined by anti-idiotype antibodies production. Allergy 72: 45-51.

26. Jenkins RE, Yaseen FS, Monshi MM, Whitaker P, Meng X, et al. (2013) $\beta$-Lactam antibiotics form distinct haptenic structures on albumin and activate drugspecific T-lymphocyte responses in multiallergic patients with cystic fibrosis. Chem Res Toxicol 26: 963-75.

27. Wang HY, Xiao Y, Han J (2005) Simultaneous determination of carvedilol and ampicillin sodium by first-derivative fluorometry in the presence of human serum albumin. Anal Sci 21: 537-40.

28. Schmidt PK, Krohn RI, Hermanson GT, Mallia AK, Gartner FH, et al. (1985) Measurement of protein using bicinchoninic acid. Anal Biochem 150: 76-85.

29. Pauillac S, Naar J, Branaa P, Chinain M (1998) An improved method for the production of antibodies to lipophilic carboxylic hapten using small amount of hapten-carrier conjugate. J Immunol Methods 220: 105-14.

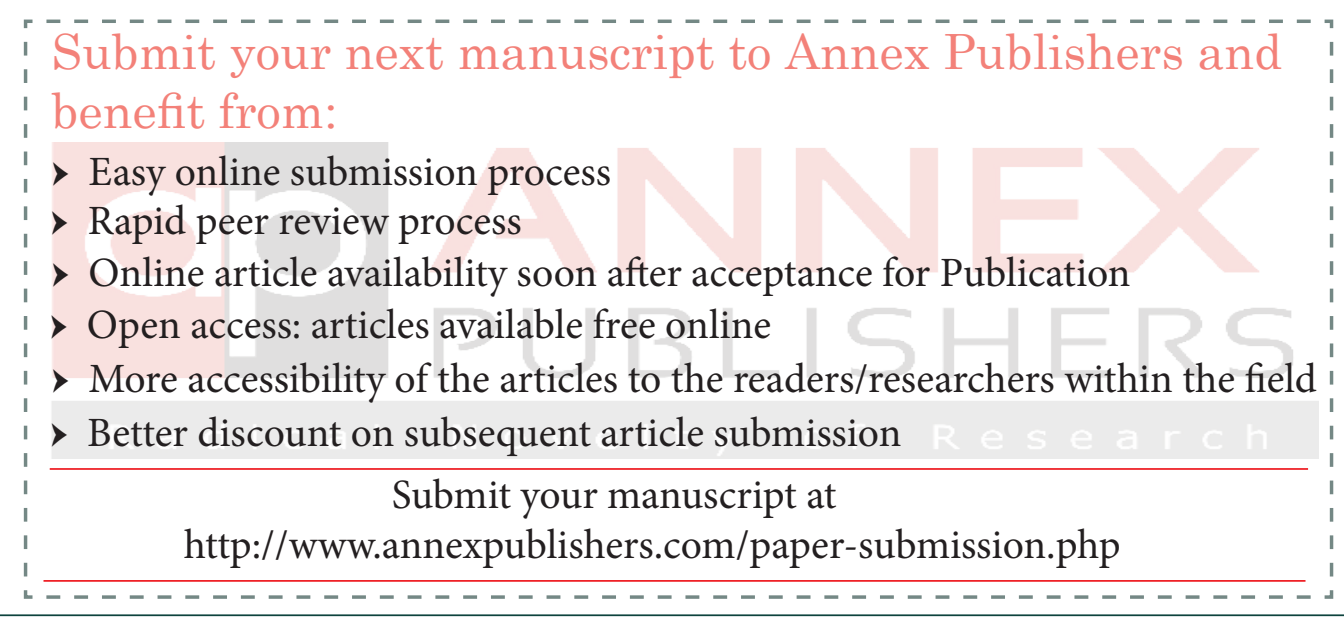

